\title{
9. New Caledonia and Vanuatu Differences defined in a student reporting venture into the Pacific
}

\begin{abstract}
A reporting field trip by Australian journalism students to New Caledonia and Vanuatu in mid-2014 produced markedly differing impressions of the neighbouring island societies, linked to their 'independence' status - one as an integrated territory of France, the other as an independent state. The field trip, one of a series from the Queensland University of Technology, aimed at developing reporting skills through work in unaccustomed territory, especially different cultural settings. Over 17 days, six students and the coordinator, and author of this article, generated 18 feature-length reports for online outlets and a radio documentary. The article synthesises the collected work from the field, producing a thematic statement of findings. It records broad consensus in New Caledonia in favour of enacting the Matignon and Noumea Accords on independence, while noting an undercurrent of unresolved conflicts. It characterises public life in Vanuatu in terms of a democratic spirit, and the invocation of traditional ties within society, as the country grapples with problems of development and impacts of the outside world. This work is interpretative, concerned with identifying processes underlying events in daily news. It is proposed as a first step towards a scholarly construction of meta-analyses of the interpretative and informative power of journalistic reporting.
\end{abstract}

Keywords: Australia, conflict reporting, culture, democracy, development, field trips, France, independence, journalistic practice, New Caledonia, Vanuatu, work integrated learning

\section{LEE DUFFIELD}

Queensland University of Technology, Brisbane

\section{Introduction}

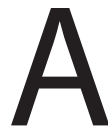

REPORTING field trip by Australian journalism students to New Caledonia and Vanuatu produced some markedly differing impressions of the neighbouring island societies, linked to their 'independence' status - one as an integrated territory of France, the other as an independent state. Lee Duffield, an academic and former overseas correspondent coordinated the project for the Queensland University of Technology. As an exercise in professional preparation, it gave the reporters a stiff test in the field, performing itinerant journalism away from familiar territory, with the added stimulus of working across cultures. 
The objective of the operation was to update main issues from those locations. It became a fairly hectic, realistic exercise in overseas journalism, over two weeks in mid-2014-June 24-July 7. The exercise was in collaboration with the Pacific Media Centre (PMC) at Auckland University of Technology, New Zealand, where the group spent four more days, July 7-14, for debriefing, additional backgrounding sessions with journalists or researchers there, and production work at a newsroom. Six student reporters had been selected, a competent team, who were mostly postgraduate students or in their final Journalism year.

Their task was to produce an online portfolio, 'South Pacific Special Report', for the campus-based publication QUT News. The site carries text, and audio or video publications. Eighteen articles were published, e.g. on the dispute over independence and impacts of nickel mining in New Caledonia; tourism and culture, and keeping the peace in Port Vila, (www.qutnews.com/2014/07/\#. Vp27MUYnlBc). A 'South Pacific Special Report' was broadcast on Brisbane multi-cultural radio 4EB-FM on 22 July 2014. Two extended articles by this writer were published in EUAustralia Online: European news for Australia; the publication at the time drawing 300000 site visits p.a., www.euaustralia.com, 12 July 2014 and 17 August 2014. Output was provided also to the PMC, which republished a selection of the reports, www.pmc.aut.ac.nz, 20 June 2014, 23, 24, 29 July 2014. The Appendix lists the reports published by the team members.

\section{Background to reporting field trips}

The venture was the 19th in a series of field trips for Journalism students since 2000 , providing course credit, seen as highly useful professional preparation because of the way such experience, taking place away from familiar supports, would focus the mind on practice. Student groups previously had gone to Southeast Asia and China, New Zealand, the European Union, and Papua New Guinea. The pedagogical foundations of the series have been described in successive articles by the writer, notably in the Pacific Journalism Review (Duffield, 2014, 2008), placing it in the context of internationalisation of the curriculum, and workplace-integrated learning. Similar projects run by the University of Queensland have referenced these field trips (see Woolley, 2015).

\section{Reporting in the South Pacific}

The 2014 operation would be distinctive and different because of its South Pacific setting. Hadlow in PJR (2010; also quoted in Duffield, 2015, p. 3) listed some of the features and characteristics familiar to watchers of the region and its media; beginning with 'geographical remoteness, small populations and vast sea distances', and a set of contrasts: 'That a region so wealthy in languages, cultures and social traditions could also be a place of coups and tensions and where media freedoms are often trampled upon, is also little known to many casual observers.' 
The themes of Pacific media, reflecting lives of the island communities, are often characterised as a story of crisis, in the sense of mixing danger and opportunity. Put another way, problems and conflict provide part of the paradigm for understanding the field for news, while a cultural richness, a 'Pacific way', offering opportunity and hope for the future, provides the balance. For journalists from outside it can be elusive. All efforts were made in three preparatory sessions in the case reported on here, to help members of the reporting team make ready for that. The debriefings in Auckland would add more substance, following up questions brought back immediately from the field, especially in interpreting the cultural backdrop to events. As in all such exercises, time was made at the start for backgrounding, including a researched paper by one of the participants, introductions to Melanesian people living in Australia, or specialist journalists with background in the region, and resourcefulness training with equipment and communication tools. The challenge then remained to deploy one's professional and personal resources to find, understand and explain the story.

For this writer, an informal workshop after the travelling phase produced a telling, even if anecdotal observation. Did the participants see a difference overall between what they found in their reporting in New Caledonia and in Vanuatu? The uniform response would characterise the former somewhat as a field of tension, conflict or resentment, the latter as also a field carrying problems but ones being confronted in a better spirit. The reportage itself would reflect much of this, a difference in the level of openness or quality of information readily given; in New Caledonia a sense of being in a place where relations are unresolved, and in Vanuatu of being privy to some free discussion over problems the country was having to face.

This comparing of notes within the reporting team led the writer to inject an element of doubt into a round-up on New Caledonia: 'The mood in New Caledonia, the racially and ethnically divided French territory of the Southwest Pacific, is there for the outsider to easily sample. It has great promise, with a studied accord for getting to some form, or other, of independence; and in other ways it does not feel good' (see Lee Duffield, Appendix). The situation in Vanuatu, on the other hand, was characterised as grappling with modernisation and outside influences, including efforts expressly to apply traditional cultural ways for handling change.

\section{Reporting practices}

As reportage, the writing from the field would be more impressionistic than interpretative, though fortified by the consultation and sharing of impressions with a colleague group, and was in the tradition of journalistic writing where the reporter tells the story plainly 'as they see it'. The reporting practice that would produce the above qualified observations about New Caledonia and 
Vanuatu was fitted to the circumstances of the group's deployment. Essentially it was an application of news values with an admonition to seek out where possible and allow for longer-term background and cultural factors not available on the surface. The imprecation, 'Don't be a parachutist or firefighter', is directed especially at unversed and unbriefed reporters arriving in unfamiliar terrain for a crisis, like a violent uprising. In part-defence of that, standing doctrine in the Western news tradition may insist that news can be universalistic, provided there is best practice: appraisal of the quality of sources, ability to check, exploiting transparency in the field of inquiry and due scepticism. It also insists on journalists knowing the field they are in, or at least being briefed well, more possible this century through online sourcing; see for example Van Druten's (in Duffield and Cokley, 2006, pp. 53-76) idea of the 'neo-firefighter', advocating high professional standards in preparation for fieldwork.

However, in the present case the group task was to refresh information on ongoing processes in the news, through mostly softer writing or feature material, in fact without the option, or time to attend events that generate hard news. Whereas the chief journalistic way of covering process, is to report news of successive events, good amenability can be provided to audiences through offering more, in a slower time frame: news features, scene-setting, analysis and commentary. The shortcomings of events-driven news coverage have been dealt with often; succinctly in the case of an insightful commentary from Mayer (in Henningham, 1992, p. 37): 'Hard news can't handle process. It is reductionist, treats events and politics in an ahistorical way, as a glut of occurrences; and cannot cope with any long-term historical processes, nor with complexity.'

The pre-arranged briefings and interviews for New Caledonia were with the Australian Consulate-General; a spokesperson for the conservative political party, and Caldoche interest, the Rassemblement-UMP, (Caldoches being the long-term French settler society); the news director of the Kanak station Radio Djiido (broadcasting for the Kanak, Melanesian community), and the director of the Tjibaou Cultural Centre. Late arrangements to meet two French military reserve officers in Noumea fell through over a breakdown in messaging. A further encounter with the Kanak movement would be 'offshore', an appointment with two senior figures at the headquarters of the international agency, the Melanesian Spearhead Group, in Port Vila. Other appointments in Vanuatu were with the editors of the two principal newspapers; with a non-governmental agency, the Pacific Institute of Public Policy (PiPP); photojournalist Ben Bohane, and the proprietor of Tanna Coffee, Terry Adlington.

Several leads were improvised, for example: interviewing members of a motor cycle club spotted outside of Noumea, (considered newsworthy as at the time such gatherings were forbidden under 'anti-bikie' legislation in Queensland, the reporters' home market); cold calling at the Vanuatu police headquarters, 
producing some well-sourced material on community policing; a report on the expanding cruise ship industry taking world tourism to outer islands, prompted by the presence of a ship in Port Vila Harbour; a visit to the Vanuatu National Cultural Centre, and to a kava bar. The itinerary was confined to Noumea and Port Vila except for short journeys outside the capital cities mostly for recreation. In New Caledonia one member of the party had French language, sufficient for most organising purposes, and one case requiring translation. None of the group spoke the Vanuatu lingua franca, Bislama, but English proved most common there.

\section{Synthesising the outcomes of reportage}

As an inquiry into journalistic practice, the present article acts on the premise that journalism will unearth, analyse and edit such large volumes of information on a daily basis it becomes a leading source of historical knowledge; especially with the advent of massive online databases, (see Duffield 2002, pp. 277-84).The article is not presented as being itself an artefact, exemplar or instance of published journalism researching and telling history. It is a description, commentary and reconstruction of such practice, one that shows how journalism may be applied to serve such purposes as to record history; in the case of the journalistic output of the seven reporters on the South Pacific tour. In this, it remakes the collection of reports, combining them to produce an overall interpretative account of the situation in the two societies put under review for initially journalistic purposes. The following then, is a digest of information, and treatment of information obtained through a synthesis of the content of reportage performed by the seven journalists.

\section{New Caledonia}

In the New Caledonia coverage, background information is given on the 'French' and 'Kanak' communities, majorities respectively in different geographical locations. In the scene-setting, townscapes are able to be represented as 'like a dozen French towns ... (where) with a little imagining it might be somewhere around Nice'; 'knots of people ... mingle at the salubrious Place des Cocotiers ...'; 'small groups of young, black unemployed wait uneasily around job centres and a training school' (see Duffield, Appendix). Also part of the setting; in the local news, an acid spill at a nickel mine has provoked violent demonstrations, with road blocks by crowds of youths, stoning passing buses, two police officers shot, non-lethal, and 80 arrests with the Gendarmerie out pursuing more suspects.

All informants agreed there were two dominant subjects to contemplate: implementation of the Matîgnon (1988) and Noumea (1998) Accords, setting out a roadmap for independence; and the lucrative, expanding nickel industry. The calculus and discussion is overwhelmingly carried out in terms of the strictures of the formal, legal agreements; but this can be misleading, as there are signs 
also of more visceral politics. Key statistics describe the political impasse in New Caledonia. The Melanesian Kanaks make up just over 40 percent of the population, corresponding with total representation of their various 'pro-independence' parties in the New Caledonia parliament, the Congress (38.2 percent, 25 seats). European French, including Caldoches, have just under 30 percent of total population, but have been able to mobilise voter turnout and build a social coalition, resulting in close to 57.5 percent ( 29 seats) for the 'anti-independence' bloc. 'Others' in the population of just under 270,000 include a third major grouping, Polynesian, nearly 11 percent. One more statistic hangs over the debate on New Caledonia independence; high unemployment, conservatively estimated at 13.8 percent to 17 percent. Estimates exceeding double that average for 'Kanak' youth are uncontested. (Sources: www.tradingeconomics.com/new-caledonia/ unemployment-rate; www.cia.gov/library/publications/the-world-factbook/geos/ nc.html; www.lowyinterpreter.org/post/2016/01/08/New-Caledonia-censusraises-thorny-political-questions.aspx; www.isee.nc/component/finder/search? $\mathrm{q}=+$ chiffres + cles\&Itemid=101).

\section{Three discourses}

An overall narrative will have two alternative themes or treatments for the independence issue, and a third based on the mining issue. On one hand there is the arithmetic and a pragmatic argument about a form of independence. The 'French' have kept an upper hand, by democratic means; they invest and provide state finances from national budgets; the state-provided infrastructure is excellent by the standards of Pacific states, with an increasing share going to Kanak citizens, e.g. for education; France contributes to regional security and stability, and the Accords reached among the communities and the metropolitan government are being allowed to run their course. These binding agreements commit New Caledonia to a referendum on independence by the end of 2018 . In the meantime there is power-sharing, with Kanak Ministers in the present government. Political civility prevails. The form of the eventual referendum will be whether to transfer a balance of five remaining powers to the Noumea parliament-foreign affairs, justice, public order, currency and defence. Failure to conduct the vote, occasioning direct intervention from France, is broadly rejected as only a last resort. Journalists are told, that whatever residual rancour exists, there is some consensus backing this measured-out solution as a main chance which must be tried.

On the other hand, there is the second treatment, that adopts a Kanak perspective, built on a key point common to all discourse on decolonisation: they were there first. In the Kanak villages, the tribus built among the wild greenery of country areas, that argument prevails; ultimate power must be restored to original inhabitants. They have found outside support, e.g. in sympathetic hearings from the 
United Nations Decolonisation Committee, where they have also argued against claims by Caldoche representatives for recognition of their own generational status, since first colonisation in the $1850 \mathrm{~s}$. The Kanak case seeks to promote 'cultural power' following the dicta of the late independence leader Jean-Marie Tjibaou, who organised the first festivals for cultural revival, arguing that preservation of the original culture would clearly identify a continuing native society, that should warrant having its independence restored.

The third field of discourse is built around mining and refining nickel, New Caledonia being among its five main producers. As was established in the 2014 reportage, this resource industry is undergoing massive quantitative expansion. The long-established nickel company SLN, 60 percent owned by the French company Eramet, with French government interest and local investors holding 4 percent, uses the refinery located in central Noumea. Of two much bigger, and newer undertakings, the Koniambo mine in the North of the main island, Grande Terre, is 51 percent publicly owned through the provincial government there, the balance of 49 percent taken over by the Canadian company Glencore, previously Glencore-Xstrata. In the other case, Goro mine in the South of the island has a negligible public holding, virtually wholly owned by Vale in Brazil. Nickel already provided over 93 percent of total exports from New Caledonia in 2007, valued at US\$2.11billion. (Source: www.isee.nc/component/finder/se $\operatorname{arch} ? \mathrm{q}=+$ chiffres + cles\&Itemid=101).

Elements in the debate surrounding nickel: The two large mines are in provinces with substantial Kanak populations, with Kanak parties dominating or prominent in local assemblies, highly sensitive to periodic accidents and environmental despoliation, and to industrial problems among the workforce. (Social tensions and disputes over this situation are identified in the field coverage- see Simpson and Veivers, Appendix.) All parties understand that government must obtain revenue from the mines to maintain a high standard of services, and a high nominal standard of living - where per capita Gross Domestic Product (GDP) in New Caledonia is comparable with Australia's (Source: www.tradingeconomics. com/new-caledonia/gdp-per-capita). However, the government is bound by initial incentives contracts exempting the new mines from taxation, for 15 years after they reach agreed levels of full production. The mines commenced production in 2010 and 2014 respectively, entered a period of weaker commodity prices, and have not shown themselves likely to go quickly towards that full capacity. The frustration of the political community over this blocking-off of anticipated revenues, is complicated by disputes over whether to apply the eventual proceeds through a sovereign wealth fund, or immediately towards poverty relief and employment. Conservative interests will advance a 'mining-related' argument against independence: powerful multi-national companies in effect would recolonise a small and weak independent state; better for that power to remain with France. 


\section{Sources and testimonies}

Whereas journalism is not simply a bare recording and indexing of facts, but creative work sensitive to nuance and tone, interpreting information and the way things are said; much of the 'sense-making' by journalists will depend on the rhetoric or images in play, inadvertent comments, or unexpectedly getting a document. The following is a selection drawing on the way informants explained their situation.

Kanak leaders have publicly committed to the orderly road towards an ambiguous goal of independence - though inclined to make clear that the process must deliver a final outcome which in their eyes will be just. The head of the FLNKS - Kanak delegation at the Melanesian Spearhead Group (MSG), based at Port Vila, Jimmy Naouma, told his interviewer it was an 'efficient pathway to decolonisation'. New Caledonia would become an economic leader in the region and 'doorway to Europe', when full independent government was achieved: 'Those powers will come across, we are convinced'. 'We are getting ready for independence', he said. Romain Hmeun, news editor on the Kanak community radio, disavowed that the resentments within his community would upset the plan for a prosperous future, saying the Matignon accords had produced a 'consensual system of government, which means both sides govern together, working for everyone'. 'The Matignon accords set this up as a frame of law and even with independence they would be a protection of people's interests', he said. As for the islands' history of violent confrontation, the gap in wealth between communities was closing and people had no appetite for conflict: 'The real victims of history have been the Kanaks, but now the younger generation see the Caldoches as equals; they have no wish for revenge if independence is granted'. Yet, as if held in reserve, there is cultural power, as embodied in the popular radio outlet itself, taking up freedoms guaranteed by the Accords: 'This is a people not just a community; people can speak freely and that's where the power comes from; the station is part of a symbolic and historical movement' (see Kelly, Appendix).

Vaea Frogier from the conservative political party, the Rassemblement-UMP, represents the Caldoche interests in this coverage, and similarly, takes up the consensual themes - while holding some quiet insistence in reserve. 'We all have to be able to talk and find a solution,' she says. 'We recognise one another.' There is the same focus on a strong economic future built on the nickel industry, a settlement of conflicts over it, and getting revenue from it: 'We will not find a political solution unless a nickel solution is found.' However, Frogier also will engage directly with 'real life' conflicts of interest and opinion, if somewhat masked by the restrained discourse over an organised settlement. As to, 'Who was here first?': The European French, the Caldoches in particular, must be able to share a right to the land with Kanaks: 'Both are legitimate interests; the country belongs to both; in a democracy, if you live here you have a right to vote' (see Kelly, Appendix). 
Also prepared to engage is Rose Wete, a Kanak identity who calls up bad memories of policies extending into the $1980 \mathrm{~s}$, offering the vote freely to recent arrivals from metropolitan France. 'The French were encouraging full white immigration to New Caledonia and making Kanaks a minority in our own country,' she says. New laws require voters to have been residents since 1998, but there were severe arguments still going on over the strategic enfranchisement of parcels of French voters, and several Kanaks not getting a vote. Wete, a senior official with the MSG, objected to claims made during elections on the 'French' side, that a vote for independence would sabotage the Matignon 'road map' and cut off economic benefits of association with France. 'My blood would start to boil...,' she said. 'They were saying we will end up like Vanuatu, we will become poor and undeveloped. Did they really think that was going to happen? These parties had all actually signed the Accord ... themselves committed to the process.' The Accord process may succeed, but until such time, 'the whole system has disadvantaged the Kanaks' (see Duffield, Appendix; Harvey, Appendix).

A conclusion might be drawn from this dialogue with reporters. Old conflicts are being dampened down, and the parties are making strong efforts, seeking to enact a settlement set out on paper, under the chairmanship of the metropolitan government, according to best principles of reasonableness. There are reservations, and actual power held in reserve, be it power to withhold full benefits of the modern economy, or to mobilise a people in opposition. That is an impression obtained: a good chance of a solution, but with conflicts pushed below the surface, and the big question, who will rule and how, unresolved.

\section{Democracy in Vanuatu}

For a scene setter at Port Vila, a retrospective passage from Richard Shears (1980, p. 53) would still resonate: 'Taxis prowled the streets waiting for a call from French, English, Melanesian or Australian shoppers. The tourist ship Sea Princess still called by... The souvenir shops displayed wooden statuettes and coral necklaces. In this country with a split personality you could still ... imagine you were in France, England, Australia, or a Pacific Island.' Within that colourful scenario the country would move on: independence in 1980, rapid population growth especially in the city, and the internet revolution, aggravating the pace of politics and change.

In Vanuatu the citizens 'don't hold back' when they debate political or social issues on Yumi Toktok Stret ('Straight-talking'), the strongly popular 'citizen journalism' site, says Royson Willie, editor of the Vanuatu Daily Post, describing it as a useful news source, which mainstream reporters pick up and check (see Veivers, Appendix). Derek Brien sees social media generating a 'broader debate and a richer debate'. He is chief executive officer of the PiPP, which works for community development, organising large gatherings to debate public issues. He 
sees the 'independence' generation now being replaced with younger and better educated leaders, and use of all media is part of that: 'Before, those in power operated in a vacuum with less inclination to share. Now there are political actors, not necessarily MPs, on the scene, and the politicians see that it is beyond their control; they might not be part of the conversation... There is simply no widespread opposition to people having access to communication and technology' (see Simpson and Clarke, Appendix).

Journalists themselves, like Royson Willie, affirm the impression of a climate of free speech. In part they have been able to make progress, for instance reporting on cases of official corruption without interference, through calling in help from outside bodies like the Commonwealth Press Association. They have weathered passages of even physical bullying, Willie himself assaulted in an infamous incident, and witholding of information by government. As two of the Australian reporters put it in a despatch: 'Media workers in Vanuatu say they are upsetting the usual story of a small developing country, by getting more freedom of information not less - though it has never been easy.' (see Simpson and Clarke, Appendix). Eveylyne Toa, editor of the Vanuatu Independent, and president of the Vanuatu Media Association, agrees an assertive media is succeeding: 'We believe in the right for our own people to be informed; our aim is to be informative and educational,' she says, and recommends a democratic antidote to repression: 'We had one minister who would come in and bang his fists on that desk, and if they do that we will tell the people ... Now we have more freedom, but we must also be responsible.'

The existence of pluralistic media services and open public debates cannot of themselves generate an ideal state of society but in some sense are a precondition for it, signifying healthy change. To take the description of the situation briefly onward, to early 2016, and the lead-up to the Vanuatu elections; it would be a vote produced by no less a crisis that the gaoling of 14 MPs, including Ministers, for corruption offences, but accompanied by robust and open campaigning, including through social media. If the system of electoral politics appeared somewhat immature, with 36 political parties covering many strands of policy or regional interest, it also appeared to be well alive, 261 candidates contesting the 52 available seats, (Vanuatu Daily Digest, 11 January 2016). The voting would produce changes, some 'out with the old; in with the new.'

\section{Discourses: development and custom}

The 'freedom' context is one way in which the independent state of Vanuatu presents itself to visiting media, together with two other important agendas: problems of poverty and development, and social tensions; and holding to custom and tradition as a way of coping with pressures of modern times. Issues raised in open forums, like the heavily-used online election debates, provide a 
description of a developing country with some advancing problems, yet also lasting strengths and potential for success. Rural villages house 75 percent of the population of almost 250,000, giving security and support, but themselves lacking in amenities and government services, with deteriorating roads and public buildings including schools. The capital city, Port Vila, where population has increased nearly ten-fold to 50,000 since World War II, exhibits problems with urban drift, people moving in from the islands: pressure on land use, high unemployment among youth, poor housing, social tensions, more crime. On the key measure of infant mortality, deaths per 1000 live births, the country rates at 15.7, compared to the world average of 35.4, or elsewhere in the Pacific, Papua New Guinea (38.55), Australia (4.37). Compared to New Caledonia, not so segmented into distinctive ethnic identities, there is one, Melanesian culture, fragmented into language and island groups, but thinking as a whole, as the $\mathrm{Ni}$ Vanuatu, people of the country. (Sources: www.cia.gov/library/publications/ the-world-factbook/ ...; also WHO statistics putting the global rate at 32, www. who.int/gho/child_health/mortality/neonatal_infant_text/en/).

A police officer outlines a community outreach program taking officers into townships or villages, in cooperation with chiefs, then despairingly reports on the frustration of police unable to respond to street crime in Port Vila: 'I am sorry to tell you that we don't have enough resources to deal with what is happening now... Youth get into mixed groups, from the different islands, and do not have the same controls as in their home areas ... We get issues like violence towards women and assault. The range of crime has now extended to breaking into houses and properties.' While crime rates remain moderate on any world standard, and police have access to training and assistance from other national forces, they become paralysed if unable to patrol because there is no petrol, or being without adequate communications, must resort to using their private mobile phones (see Clarke, Appendix).

Vanuatu, unlike New Caledonia, has no nickel mines and no France to bankroll a higher living standard. Per capita GDP remains at a little under US\$2,530, (against US\$38,896 in New Caledonia). Opportunities do exist in tourism, replanting neglected coconut plantations, or value adding by more processing of farm products. To make change requires finding ways to get things done, often still by going to traditional authorities. Derek Brien of the PiPP explained difficulties faced in taking economic advantage of new communications technology: 'The next big break is broader access to the internet through mobile phones but there is a long way to go for that in rural areas...' Installing telephone towers and lines had met with suspicion over alienating the customary use of land, requiring concentrated diplomacy by industry and officials: 'The phone providers had discussions with traditional land owners to ensure they were happy with the phone infrastructure ... In this part of the world it's all about communicating by 
telling stories. It's about putting everything we do in fairly plain language ...' (see Veivers, Appendix).

Resorting to village tradition and authority might be the wisest available course to head off social break-down under great pressure for change, says the PiPP communication director, Ben Bohane. He had seen that when conflicts arose between communities, it was always the custom to try and get an amelioration, symbolised by an exchange of valuables - hand-crafted mats or betel nuts. It becomes a joint effort, avoiding pay-back, so 'the peace tends to hold' (see Mahoney (2), Appendix). The Ni-Vanuatu preserve a complex set of kinship relations and each one's island of birth remains a key identifier. Political candidates preparing for election often include a policy supporting recognition and consultation by government with the Malvatumauri, the National Council of Chiefs.

Against that, impacts of dislocation like urban drift and the spreading, globalised cash economy are manifest. A shopper in the car complains about cheap manufactures: 'People cook with a lot of rice; we can still get Australian rice but it is dearer, and now people are offered Chinese rice, which is a poor quality one with small grains, but very cheap, so they buy it, and I think it is not good for them. Even the iron pots are not as good; they were French once, but now Chinese, cheaper but not as heavy and long-lasting, not as good for the cooking' (see Duffield (2), Appendix). Widespread recreational use of kava, the mildly sedative drink, has replaced the original restricted and ceremonial use, reserved mostly for elders. Edgar Hinge does not like it. He takes visitors around the spacious National Culture Centre, explaining the antiques and later traditional artefacts, drawing stories in a sand-pit. As for kava, he says: 'It is a problem with people over-using kava because when they drink too much they become creative and say that they will achieve all these things. But the next day they don't remember and they achieve nothing because kava has affected their thoughts' (see Veivers (2), Appendix).

\section{Summary and conclusions}

This article has sought to analyse a portfolio of journalistic articles obtained on a reporting field trip to New Caledonia and Vanuatu, to extract themes, and support the assertion that media coverage is adaptable to providing convincing historical accounts. As a case study it draws on a collaborative review and recapitulation by journalists involved in the coverage; then a revisiting, re-editing and revising of information used in the published accounts. It is in effect a first step towards producing a meta-analysis of the interpretative and informative power of journalistic reporting for use in scholastic work. It is concerned with identifying processes in the news, extending beyond the limitations of 'component' events of such processes, reported piecemeal on a daily news basis. The reporters had privileged access to helpful, well informed sources. The journalistic focus on 
processes in public life, culture and society, approached on a documentary or commentary basis, delivered a documentary radio program and a set of feature articles well suited to the format of their online outlets. It retained a conventional journalistic focus on establishing facts, on what was new, and on providing a reasoned and fair analysis. The review here, has synthesised the product, with adjustments such as some further fact-checking, to extract an overall interpretation, built on differences between the two neighbouring Pacific Island societies. An essential difference seen is between the as yet unresolved independence issue in New Caledonia, depicted in terms of a peaceful and consensual process, but with undercurrents of tension and conflict; and the struggle of independent Vanuatu, its citizens grappling with their issues of economic survival, justice, freedom and authority - between their own hands.

\section{References}

Cap Bocage (2014). Documentary, Director-Producer Jim Marbrook; New Zealand International Film Festival, 17 July 2014-6 August 2014, Auckland. Retrieved from www.nziff.co.nz/2014/auckland/cap-bocage/, (19.1.16).

Central Intelligence Agency (CIA), Langley Va, World Factbook, New Caledonia, www. cia.gov/library/publications/the-world-factbook/geos/nc.html; www.cia.gov/library/ publications/the-world-factbook/fields/2091.html\#nh, (18 January 2006).

Duffield, L. (Ed.) (2016, January 14). EUAustralia Online: European news for Australia. Retrieved from www.euaustralia.com

Duffield, L. (2015). Twenty years on the front line of regional identity and freedom. Pacific Journalism Review, 21(1), 18-33.

Duffield, L. (2014). Student reporting abroad: a journalism project built on internationalisation', Pacific Journalism Review, 20(2), 205-223.

Duffield, L. (2009). Berlin Wall in the news: mass media and the fall of the eastern bloc in Europe - 1989, Saarbrucken, VDM: 267-75. See also, http://eprints.qut.edu. au/3904/, pp 273-79.

Duffield, L. (2008). Student reporting abroad: An international programme called journalism reporting field trips, Pacific Journalism Review, 14(2), 102-122.

Hadlow M. (2010), 'Editorial: Great is Truth', Pacific Journalism Review, 16(2), 2010: 5-8. ISEE (Institut de la statistique et des études économiques de Nouvelle-Calédonie). (2016) Noumea, "Chiffres clés" [Key Figures]. Retrieved on January 18, 2016, from www. isee.nc/component/finder/search? $\mathrm{q}=+$ chiffres + cles\&Itemid=101

Lowy Institute, Sydney (2016). The Interpreter: New Caledonia census raises thorny political questions. Retrieved on January 8, 2016, from www.lowyinterpreter.org/ post/2016/01/08/New-Caledonia-census-raises-thorny-political-questions.aspx,

Mayer, H. (1992). Images of politics in the press. In Henningham, J. (Ed.), Issues in Australian journalism (pp. 36-46). Melbourne, Vic: Longman Cheshire.

Trading Economics, NY / Lisbon (2016). New Caledonia unemployment rate, Retrieved on January 18, 2016, from www.tradingeconomics.com/new-caledonia/ unemployment-rate 
Pacific Media Centre Online, AUT, Auckland. (2016). www.pmc.aut.ac.nz

QUT News, QUT, Brisbane (2014, July 28). Exploring the South Pacific. Retrieved on January 19, 2016, from www.qutnews.com/2014/07/\#.Vp27MUYnlBc

Shears, $R$ (1980). The coconut war: the crisis on Espiritu Santo. North Ryde, NSW: Cassell.

Van Druten, R. (2006). 'Neo-firefighters': a new model for international news correspondents in the changing context of world journalism. In Duffield, L., and Cokley, J. (Eds.), I, journalist: coping with and crafting media information in the 21 st century (pp. 53-76). Sydney, NSW: Pearson Education Australia.

Vanuatu Daily Digest (2016). Bob Makin (ed.), Port Vila. Retrieved on January 20, 2016, from https://vanuatudaily.wordpress.com/

Woolley, B. (2015). Developing skills in international communication and international reporting though work integrated learning courses. Australian Journalism Review, 37(2), 187-204.

Acknowledgements: Members of the QUT team reiterate their thanks to the director, Professor David Robie and others at the Pacific Media Centre, Auckland, especially the welcoming choir, the late school manager, Kevin Upton; senior lecturer Greg Treadwell; and 'briefing officers' Sandra Kailahi from TV New Zealand, Alex Perrottet of Radio New Zealand, and Anna Majavu, then contributing editor on the PMC's Pacific Media Watch freedom project. Thanks again also to the contacts and interviewees in the field.

Dr Lee Duffield is a senior lecturer and postgraduate journalism coordinator at the Queensland University of Technology in Brisbane. A former overseas correspondent with Australia's public broadcaster $A B C$, he runs an international journalism programme, taking student groups both to European countries, Asia and the Pacific. He is on the editorial board of Pacific Journalism Review and a research associate of the PMC. He publishes extensively on Europe and media, development journalism in the Pacific, new media, and journalism education.

I.duffield@qut.edu.au 


\section{Appendix: Project published articles}

The articles from QUT News are on either of two pages: www.qutnews.com/2014/07/\#. Vp3M50YnlBc, (Retrieved on January 19, 2016), or www.qutnews.com/2014/07/ page/2/\#.Vp3ceUYnlBd (retrieved on January 19, 2016).

Emma Clarke (2014, July 8). 'Good cops' challenge: Keeping the peace in Port Vila, QUT News, Brisbane.

Emma Clarke (2) (2014, July 23). Impacts of 'Big Nickel', QUT News, Brisbane.

Lee Duffield (2014, July 12). New Caledonia: Getting ready for independence, EUAustralia Online, Brisbane, L. Duffield (Ed.). www.euaustralia.com/2014/07/. (Accessed 19 January 2016). Also as, New Caledonia notebook: Getting ready for 'independence' (29 July 2014), Pacific Media Centre Online, AUT, Auckland, www.pmc.aut. ac.nz/articles/new-caledonia-notebook-getting-ready-independence. (Retrieved on January 19, 2016).

Lee Duffield (2) (2014, August 17). Vanuatu: Freedom, custom and change, EUAustralia Online, Brisbane, L. Duffield - Editor. www.euaustralia.com/2014/08/ (Retrieved on January 19, 2016).

Harriet Harvey (2014, July 9). Melanesian Spearhead Group wants action on New Caledonia, de-nuclearisation and climate change, QUT News, Brisbane.

Harriet Harvey (2) (2014, July 9). Celebrating Culture: Vanuatu Cultural Centre creating pride in the community, QUT News, Brisbane.

Harriet Harvey (3) (2014, July 10). An Aussie taking the Pacific coffee industry by storm, QUT News, Brisbane.

Nick Kelly (2014, July 3). Getting justice and settling differences in the French Pacific, QUT News, Brisbane.

Nick Kelly and Jaleesa Simpson (2014, July 3), Tjibaou Cultural Centre at Noumea: tribute to a leader, QUT News, Brisbane.

Jane Mahoney (2014, July 3). Linking Up: Australia likes New Caledonia but is not buying into its troubles, QUT News, Brisbane.

Jane Mahoney (2) (2014, July 10). Profile: Pacific journalist interested in social justice, QUT News, Brisbane. Also in Pacific Media Watch, PMC (July 23) www.pmc.aut. ac.nz/pacific-media-watch/region-pacific-journalist-interested-social-justice- 8872

Jane Mahoney (3) (2014, July 3). Motorbikes: A Passion, Unbanned in the Pacific, QUT News, Brisbane.

Jaleesa Simpson (2014, July 3). Kanak radio station giving 'pro-independents' a voice, QUT News, Brisbane.

Jaleesa Simpson and Emma Clarke (2014, July 8). Vanuatu's optimism about media and freedom in fourth decade of independence, QUT News, Brisbane. Also as Vanuatu: Optimism about media freedom and information changes, at Pacific Media Watch, PMC, Auckland (24 July 2014). www.pmc.aut.ac.nz/pacific-media-watch/vanuatuoptimism-about-media-freedom-and-information-changes-8873

Jaleesa Simpson and Danielle Veivers (2014, July 3). Looking for work in nickel-rich New Caledonia, QUT News, Brisbane.

Danielle Veivers (2014, July 8). The future of news in Vanuatu, QUT News, Brisbane.

Danielle Veivers (2) (2014, July 9). Kava: A tradition, a business and a problem, QUT News, Brisbane.

Danielle Veivers (3) (2014, July 4). Cruising to paradise: big ships to transform the Pacific holiday business, QUT News, Brisbane.

Pacific Media Centre (PMC), AUT, Auckland (2014, June 20). QUT's Pacific student journo news bureau team heading for Auckland. 